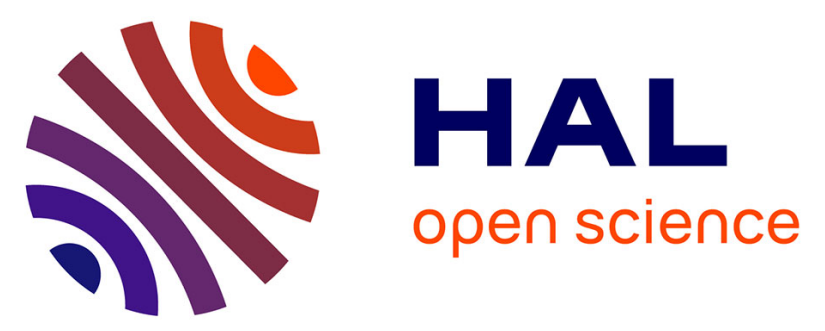

\title{
EFFECT OF ALLOY ADDITION AND IMPURITIES TO THE FRACTURE OF WELDS IN MOLYBDENUM AND ITS ALLOYS
}

F. Morito

\section{- To cite this version:}

F. Morito. EFFECT OF ALLOY ADDITION AND IMPURITIES TO THE FRACTURE OF WELDS IN MOLYBDENUM AND ITS ALLOYS. Journal de Physique Colloques, 1990, 51 (C1), pp.C1-281-C1-286. 10.1051/jphyscol:1990144 • jpa-00230303

\section{HAL Id: jpa-00230303 https://hal.science/jpa-00230303}

Submitted on 1 Jan 1990

HAL is a multi-disciplinary open access archive for the deposit and dissemination of scientific research documents, whether they are published or not. The documents may come from teaching and research institutions in France or abroad, or from public or private research centers.
L'archive ouverte pluridisciplinaire HAL, est destinée au dépôt et à la diffusion de documents scientifiques de niveau recherche, publiés ou non, émanant des établissements d'enseignement et de recherche français ou étrangers, des laboratoires publics ou privés. 
COLLOQUE DE PHYSIQUE

Colloque $C 1$, supplément au $\mathrm{n}^{\circ} 1$, Tome 51, janvier 1990

EFEECT OF ALLOY ADDITION AND IMPURITIES TO THE FRACTURE OF WELDS IN MOLYBDENUM AND ITS ALLOYS

\author{
F. MORITO
}

National Research Institute for Metals, 1-2-1 Sengen, Tsukuba 305. Japan

\begin{abstract}
Mechanical properties of electron beam welds in pure molybdenum, Mo-C, and some alloys containing $\mathrm{Ti}, \mathrm{Zr}, \mathrm{Nb}, \mathrm{V}$ and $\mathrm{Re}$ were investigated. Fracture surfaces were examined in detail by SEM and AES and microstructures also by TEM. Considerable intergranular fracture occurred in almost all the welds. But proper alloy addition and heat treatment changed the fracture mode to transgranular one. Nitrogen segregation to grain boundaries decreased the strength of grain boundaries, but carbon segregation and precipitation increased the grain boundary cohesion and increased the fracture strength of grain boundaries. Small precipitates due to comparatively low alloy addition such as $\mathrm{C}, \mathrm{B}, \mathrm{Ti}, \mathrm{Zr}, \mathrm{V}$ and $\mathrm{Nb}$ were effective to enhance the grain boundary cohesion and discussed from a standpoint of atomic C/O ratio. Sintered Mo-Re welds, which included a large number of porosities during electron beam welding, showed solution softening but fracture surfaces were mainly intergranular in the Re content of less than 13 wt\%. With an increase of Re content, twin deformation occurred at low temperatures and fracture mode changed to transgranular one.
\end{abstract}

1. Introduction

Molybdenum and its alloys are promising materials of high performance. It is well accepted that poor ductility below ambient temperature and low toughness limit more extensive application of Mo base alloys. One of the problems is, for example, anisotropy of rolling textures resulting in nearly zero ductility in the transverse direction, despite having good ductility in the longitudinal direction[1]. Another problem is the brittle behavior that is often observed in recrystallized or welded Mo and its alloys. Bend properties of electron beam welds in various Mo and alloys such as PM-Mo, EB-Mo, AM-Mo, TZM and Mo-Re(PM) were examined and microstructure and fracture surfaces were analyzed in detail[2]-[4]. In addition to the above results, a variety of electron beam welds and unwelded samples in Mo and its alloys were further examined by bend test in this study. Microstructure and fracture surfaces were examined to discuss the effect of alloy addition and impurities on the weldability and intergranular embrittlement. 


\section{Experiment}

Materials used in this study are, as listed in Table 1, a variety of powder metallurgy (PM)Mo, electron beam melted(EB)Mo, Mo-0.15\%Nb and Mo-0.56\% Nb, arC melted (AM)Mo, Mo-0.15\%V-69ppmB, Mo-1.08\%V-39ppmB and TZM(Mo-0.45\%Ti$0.094 \% \mathrm{Zr}$ ), and Mo-Re alloys (PM and EB) ranging between $0.41 \% \mathrm{Re}$ and $41 \% \mathrm{Re}$. Nitrogen content was generally less than 6 ppm and ordinary oxygen content ranged $10 \mathrm{ppm}$ to $40 \mathrm{ppm}$. Carbon content varied from less than 10 ppm to 200 ppm and more. Atomic carbon to oxygen ratio(C/O ratiol was usually less than 14. But $A M-4$ and $A M-5$ containing $V$ and $B$ showed very high $C / O$ ratio of 64.5 and 107.3, respectively. Electron beam welding was carried out by typical conditions such as beam voltage; $50 \mathrm{kV}$, beam current; 50 mA, welding speed ; $30 \mathrm{~mm} / \mathrm{sec}$ and vacuum; less than $2.7 \times 10-2 \mathrm{~Pa}$. Bend specimens with a size of $1 \times 3 \times 25 \mathrm{~mm}$ were tested at a cross head speed of $1 \mathrm{~mm} / \mathrm{min}$. Heat treatments between $1173 \mathrm{~K}$ and $1923 \mathrm{~K}$ for $1 \mathrm{~h}$ were.carried out in a vacuum below $2.7 \times 10-4 \mathrm{~Pa}$. Carburized annealing was carried out at $1773 \mathrm{~K}$ for 30 min after carbon deposition[5]. Fracture surfaces and microstructure were examined by scanning electron microscope(SEM), Auger electron spectroscope(AES) and transmission electron microscope(TEM).

Table 1 Chemical compositions of the materials in this study (wtppm).

\begin{tabular}{|c|c|c|c|c|c|c|c|c|c|c|c|c|c|c|}
\hline Element & $\mathrm{Si}$ & Mn & $\mathrm{w}$ & $\mathrm{Ni}$ & $\mathrm{Ee}$ & $T i$ & $2 r$ & $\mathrm{Nb}$ & $\mathrm{Ta}$ & $\mathrm{Cr}$ & B & c & $\mathbf{N}$ & 0 \\
\hline PM-1 & 15 & $<50$ & & $<50$ & $<100$ & & & & & $<40$ & & 7 & 6 & 16 \\
\hline PM-2 & 15 & $<3$ & & 5 & 20 & & & & & & & 5 & 6 & 18 \\
\hline PM-3 & & & & & & & & & & & & 7 & 6 & 27 \\
\hline $\mathrm{EB}-1$ & 66 & 0.9 & 280 & 0.6 & 2.4 & & 1.6 & 39 & 22 & 2.1 & & 64 & 3 & 37 \\
\hline$E B-2$ & $90^{\circ}$ & 0.4 & 57 & 31 & 11 & & 25 & 21 & 22 & 8 & & 11 & 2 & 21 \\
\hline$E B-3$ & 88 & & & 1 & 2 & & & 12 & & 1 & & 17 & 3 & 16 \\
\hline$E B-\frac{4}{2}$ & & & & & & & & & & & & 159 & 4 & 25 \\
\hline$E B-5\left(0.15 x_{3} \mathrm{~N} b\right)$ & & & & & & & & 1500 & & & & 105 & & 10 \\
\hline$E B-6(0.56 \% \mathrm{Nb})$ & & & & 2 & 3 & & & 5600 & & 5 & & 57 & 2 & 10 \\
\hline$A M-1$ & & & & & & & & & & & & 1890 & & \\
\hline$A M-2$ & & & & & & & & & & & & 7 & & \\
\hline$A M-3$ & 10 & & $<10$ & 40 & & & & & & & & 134 & 2 & 21 \\
\hline$A M-4(0.15 \% V)$ & . & & & & & & & & & & 69 & 387 & & 8 \\
\hline$A M-5(1.08 \% V)$ & & & & & & & & & & & 39 & 322 & & 4 \\
\hline $\mathrm{TZM}$ & 10 & & $<10$ & 20 & & 4500 & 940 & & & & & 119 & 6 & 14 \\
\hline PM-MR (2\%Re) & 30 & $<3$ & & 11 & 50 & & & & & 9 & & 12 & 4 & 23 \\
\hline PM-MR (4\%Re) & 30 & $<3$ & & 10 & 30 & & & & & 8 & & 7 & 2 & $1 \overline{5}$ \\
\hline$P M-M R(10 \% R e)$ & 30 & $<3$ & & 13 & 50 & & & & & 9 & & 4 & 1 & $1+$ \\
\hline$P M-M R(13 \% R e-1)$ & 160 & $<3$ & & $1 I$ & 60 & & & & & 9 & & 7 & 1 & 20 \\
\hline$P M-\mathrm{NR}(40 \% R e)$ & 40 & $<3$. & & 20 & 150 & & & & & 10 & & 12 & 1 & 66 \\
\hline $\begin{array}{l}P M-M R(5 \% R e) \\
P M-N I R(13 \% R e-2) \\
P M-N R(41 \% R e)\end{array}$ & $\left\{\begin{array}{l}(t y) \\
i(30)\end{array}\right.$ & $\begin{array}{l}0 i c a) \\
<5 \\
(<5)\end{array}$ & value) & $\begin{array}{l}<5 \\
(<10)\end{array}$ & $\begin{array}{c}50 \\
(<100)\end{array}$ & & & & & $\begin{array}{l}10 \\
(<20)\end{array}$ & & $\left(\begin{array}{c}15 \\
(<30)(\end{array}\right.$ & $\left(\begin{array}{l}5 \\
(10)<\end{array}\right.$ & $\begin{array}{c}20 \\
\langle 50\rangle\end{array}$ \\
\hline$E B-M R(0.41 \% R e)$ & & & & & & & & & & & & 37 & $<3$ & 13 \\
\hline$E B-M R(1.10 \% R e)$ & & & & & & & & & & & & 37 & $<3$ & 14 \\
\hline$E B-M R(4.90 \% R e)$ & & & & & & & & & & & & $3 i$ & $<3$ & 13 \\
\hline
\end{tabular}




\section{Results and discussion}

Welded or unwelded recrystallized Mo and its alloys exhibited a brittle behavior and premature fracture was often observed as the test temperature decreased. Ductile-brittle transition temperature (DBTT) was defined at the bend angle of 5 degrees in this study. According to the detailed work on the brittle behavior of Mo at low temperature[6], the yield stress at DBTT was considered to be the critical stress(Oc) which was nearly equal to crack propagation stress or crack nucleation stress. Fig.1 shows the relation between DBTT and the critical stress in welds and unwelded samples of various Mo and its alloys. Generally the critical stress increased with a decrease of DBTT. Welds of PM-Mo and Mo-Re(PM) with lower Re content exhibited higher DBTT and lower critical stress than those of melted Mo and its alloys. As indicated by an arrow, however, unwelded PM-Mo which was as rolled or annealed at $1173 \mathrm{~K}$ for $1 \mathrm{~h}$ had a superior ductility resulting in a full bent even at $183 \mathrm{~K}$. Welds of TZM showed higher critical stress of about $1400 \mathrm{MPa}$ at around $190 \mathrm{~K}$. Carburized annealing was also remarkably effective to improve ductility in both welds and base materials[2][4][5][7]. Mo-Re(PM) alloys exhibited superior ductile properties even at much lower temperature than room temperature. They showed a solution softening at less than 13 wt\%Re and a strong solution hardening at 40 and 41 wt\% Re both in welds and base materials. Recrystallized Mo-Re(EB) which contained 1.10\%Re and 4.90\%Re also showed higher critical stress at around $90 \mathrm{~K}$ than Mo-Re(PM) alloys. EB and $A M-M 0$ alloys such as Mo-0.12\% Nb, Mo-0.56\% Nb and AM-3 were found to have good bend ductility compared to other EB-Mo and AM-Mo. As discussed later these $E B$ and AM alloys were mainly strengthened by carbides due to considerable higher carbon content.

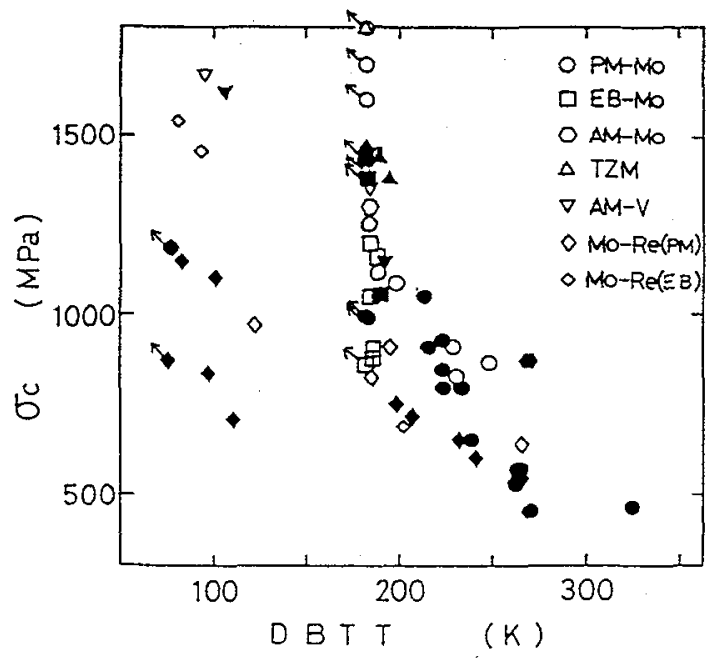

Fig.1 Critical stress as a function of ductile-brittle transition temperature in various PM-Mo, melted Mo and its alloys. Open marks denote recrystallized base materials. Closed marks denote welds. Arrow indicates that the value is higher than the each point.

Welded Mo and its alloys generally fractured in the weld metal. Crack initiated at grain boundaries and propagated mainly along the grain boundaries. Below DBTh, premature fracture was often observed so that weids and recrystallized base materials fractured before yielding at a very low stress. Carbide precipitates were generally present at grain boundaries of the welds and unwelded materials in melted Mo and its alloys except AM-2. It was generally difficult to find carbide precipitation in PM-Mo. However postweld carburized PM-1 formed very fine precipitates at grain boundaries. 
Heat treated welds in PM-1 and PM-2 sometimes exhibited an indication of precipitation in some part of intergranular fracture surfaces. As reported previously[2], [4], [7], [8], a small carbon addition by carburized heat treatment much strengthened the base materials and welds in PM-Mo due to carbon segregation and precipitation and improved the ductility except in the welds of TZM and EB-2. Micro porosities were observed in the cleavage fracture surfaces as well as in the grain boundary fracture surfaces in almost all welds. However their influence to mechanical properties seemed to be not so significant, because such sphere like defects with a very small size and diffuse density were insensitive for notch effect. As a result, sound welds were obtained in all melted Mo and its alloys and a Mo-41\%Re(PM) alloy. A number of blow holes primarily due to considerable large content of oxygen were always observed in the weld metal of PM-3 and Mo-Re(PM) alloys less than $40 \%$ Re in this study. They seemed to further enhance the embrittlement of welds. $P, S, O, K$ and $\mathrm{Ca}$ were sometimes enriched within the blow holes suggesting that oxides were formed and vaporized during welding. As welded $P M-M O$ and Mo-Re(PM) alloys exhibited significant nitrogen segregation at smooth grain boundaries. As shown in Fig.1, postweld annealed Mo-Re(PM) alloys improved the bend properties due to disappearance of nitrogen segregation by the heat treatment. It therefore confirmed that these thin layer of nitrogen enrichment was detrimental to the grain boundary cohesion and further enhanced a brittle behavior of the welds. Effect of $B$ addition in AM-4 and and AM-5 was considered to be mainly precipitation hardening combined with carbides and $V$ addition.

It has been clarified that oxygen segregation to the grain boundaries can severely embrittle a special bicrystal of high purity Mo[9]. It was also pointed out that carbon is effective to reduce the driving force for oxygen segregation to grain boundaries. When the carbon to oxygen atomic ratio (c/O ratio) was higher than 2, oxygen segregation was severely limited during recrystallization or slow cooling from elevated temperatures. Alternatively, as Iittle as 6 atppm of oxygen induced a significant grain boundary embrittlement if carbon was a very low content of 0.4 atppm. From a standpoint of this C/O ratio[10], it has been claimed that the results of vacuum arc melted Mo-Re alloys[11] failed to meet this criterion of having $\mathrm{C} / \mathrm{O}$ ratios of more than 2. It has been pointed out that the beneficial effect of Re additions between $5-8$ at\% was an artifact and was more a reflection of the inappropriately low values of ductility measured on alloy compositions outside the $5-8$ at\% Re range. It was also demonstrated that melted commercial unalloyed Mo and its alloys had a general trend of increased ductility with a function of increasing C/O ratios. They stated that it is necessary to re-evaluate brittle behavior of Mo and its alloys without an imbalance of these impurity elements[10].

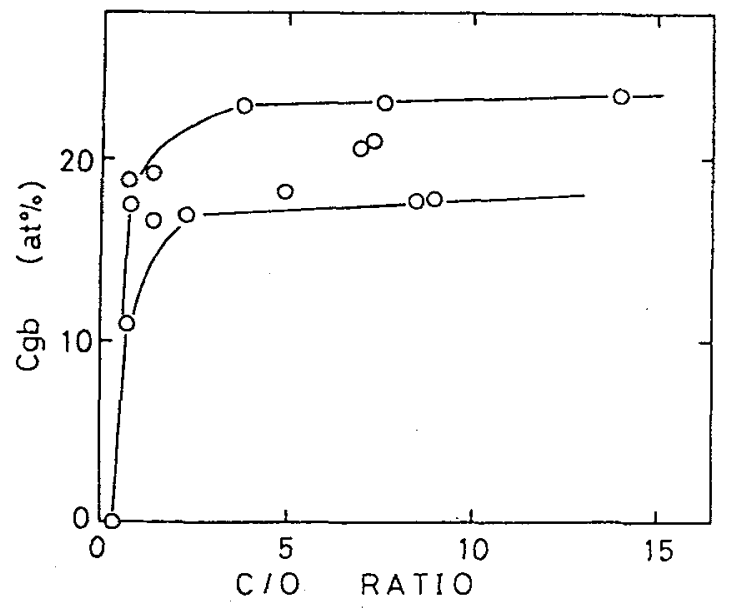

Fig.2 Carbon content at grain boundaries as a function of atomic ratio of carbon to oxygen in welds and unwelded samples in various Mo and its alloys. 
In the case of PM-Mo and Mo-Re(PM) alloys[3][4], however, it seemed different from such circumstances. Fig.2 indicates carbon concentration at grain boundaries ( $\mathrm{Cg}$ ) by AES in-situ fracture experiment as a function of atomic C/O ratio in welds and recrystalizized unwelded samples. It was clear that no carbon was usually recognized at grain boundaries of PM-Mo. As described previously, total carbon content was generally very low in PM-Mo and its alloys. Appropriate C/O ratio in PM-Mo and its alloys was lower than 1 , typical values ranging from 0.4 to 0.7 in this study. Recrystallized PM-1 and PM-2 eliminated oxygen segregation at smooth grain boundary surfaces by AES. It was also recognized that various unwelded recrystallized PM-Mo and Mo-Re(PM) alloys had a good tensile ductility more than $30 \%$ showing transgranular fracture at ambient temperature. On the other hand, carbon content at smooth grain boundaries of the samples which show higher c/O ratio than 1 demonstrated a sudden increase with $\mathrm{C} / \mathrm{O}$ ratio and a gradual saturation at about 20 at \% carbon. It was clear that the $\mathrm{C} / \mathrm{O}$ ratio more than 2 corresponded to the state of carbide precipitation at grain boundaries[2][4]. This trend showed a good accordance with the precedent indication[9], [10]. Fig. 3 shows the critical stress as a function of atomic $\mathrm{C} / 0$ ratio in several welded or recrystallized $M o$ and its alloys. Corresponding to carbide precipitation, the critical stress also increased with an increase of c/0 ratio resulting in a gradual increase of the critical stress more than 1000 MPa. Similarly DBTT showed a gradual decrease to less than $180 \mathrm{~K}$ as $\mathrm{C} / 0$ ratio increased. This difference in C/O ratios primarily comes from the fact whether carbides were formed or not. These carbides contributed not only to strengthen the bulk itself but also to enhance the cohesion of grain boundaries in the melted Mo and its alloys. However carbide precipitation was not occurred except in the case of relatively higher carbon content in $P M-M o$ and its alloys. For example, fracture surfaces in Mo-Re(EB) alloys demonstrated a number of fine carbides but those in Mo-Re(PM) alloys exhibited comparatively smooth grain boundaries with no carbides. As well known, the most effective procedure to strengthen Mo and its alloys especially for high temperature application is to alloy them with carbide forming elements such as $\mathrm{T} i$ and $\mathrm{Zr}$. But carbides were not always effective especially from the standpoint of low temperature ductility. Coarse carbides may easily play a role of crack initiation site. It is necessary to control carbide precipitation with proper size and distribution both in the bulk and at grain boundaries in order to improve poor ductility of Mo and its alloys.

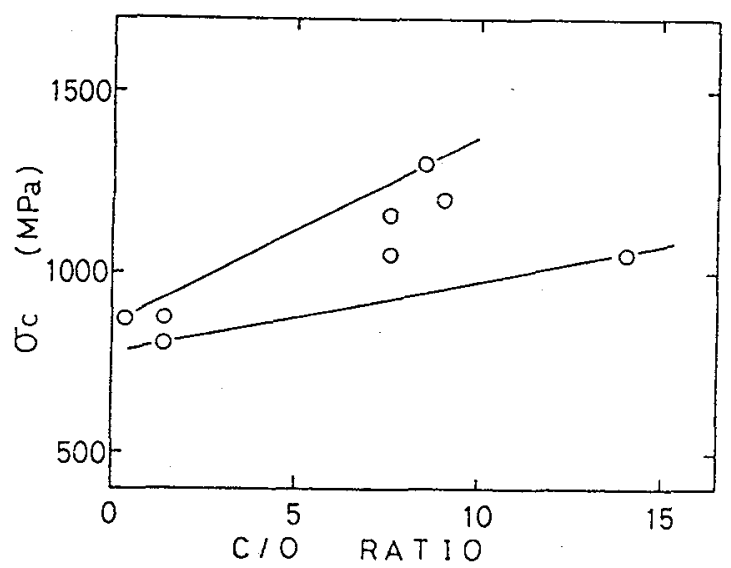

Eig.3 Critical stress as a function of atomic ratio of carbon to oxygen in several velded or recrystallized Mo and its alloys. 
4. Conclusion

Intergranular fracture surfaces of the welds of various Mo and its alloys were examined by AES, SEM and TEM. It was difficult to obtain defect-free welds in PM-Mo and Mo-Re(PM) alloys less than 40 \% Re mainly due to higher oxygen content. But sound welds were easily produced in melted Mo and its alloys and a Mo-41\%Re(PM) alloy. Effect of carbon on the weldability and intergranular fracture in various Mo and its alloys are discussed in terms of carbide precipitation. It was confirmed that appropriate carbon content for good mechanical properties was different between PM-Mo and melted Mo from a standpoint of $\mathrm{C} / \mathrm{O}$ ratio. Substitutional element strengthen or soften not only the bulk itself but also the cohesion of grain boundaries. In order to overcome poor ductility and low toughness in Mo and its alloys at lower temperature, optimum carbide content and population combined with proper alloying elements must be estimated extensively from a view of improverent of intergranular embrittlement.

\section{References}

1. J.Wadsworth, C.M.Packer, P.M.Chewey and W.C.Coons, Met.Trans. $15 \mathrm{~A}(1984) 1741$.

2. F.Morito, Proc.12th Int. Plansee Seminar, Eds. H.Bildstein and H.M.Ortner, vol.1, (1989) 313 .

3. F.Morito, ibid, vol.1,(1989) 417 .

4. F.Morito, J.Mat.Sci.(1989) in press.

5. Y.Hiraoka, F.Morito, M.Okada and R. Watanabe, J.Nuc.Mat. $78(1978) 192$.

6. A.S.Wronski, A.C.Chilton and E.M.Capron, Acta Met. 17(1969)751.

7. F.Morito, J.Less-Comm.Met. 146 (1989) 337.

8. F.Morito, J.Nuc.Mat. 165(1989)142.

9. A.Kumar and B.L.Eyre, Proc. Roy. Soc. London, A370(1980)431.

10. J.Wadsworth, T.G.Nieh and J.J.Stephens, Scripta Met. $20(1986) 637$.

11. L.B.Lundberg, E.K. Ohrimer, S.M.Tuominen, E.P. Whelan and J.A.Shields, Jr., Physical Metallurgy and Technology of Molybdenum and its Alloys, Eds. K.H.Miska et al, AMAX, Ann Arbor, MI, p.71, (1985). 